Esta revista forma parte del acervo de la Biblioteca Jurídica Virtual del Instituto de Investigaciones Jurídicas de la UNAM

\title{
¿Condenados a moverse entre fronteras? Hacia nuevos paradigmas de la regulación internacional en materia de desplazamientos internos forzados
}

\section{Condemned to Move Within Borders? Towards New Models on International Regulation Concerning Forced Internal Displacement}

\author{
Condamne a se deplacer entre les frontieres? \\ Vers de nouveaux paradigmes de reglementation \\ internationale sur le deplacement interne force
}

\section{Alan Matías Feler*}

SUMARIO: I. Introducción: la problemática de los desplazamientos internos forzados. II. Marco normativo: confluencia de regímenes y los Principios Rectores de 1998. III. Dificultades que presenta el abordaje de la problemática. IV. Respuestas intentadas en el marco de Naciones Unidas. Algunas debilidades. V. La importancia de los aportes de la Convención de Kampala. VI. Algunas consideraciones adicionales y perspectivas. VII. Reflexiones finales. VIII. Bibliografía.

* Labora en la Comisión para la Asistencia y Protección Integral del Refugiado y Peticionante de Asilo (Defensoría General de la Nación).

Artículo recibido el 15 de agosto de 2018 Aprobado para publicación el 3 de octubre de 2019 
RESUMEN: El presente trabajo analiza los desplazamientos internos forzados por causa de conflictos armados y otras situaciones de violencia. Tras exponer el marco normativo y sus principales debilidades, se presentarán algunas de las respuestas de la comunidad internacional, con énfasis en la Convención de Kampala. Seguidamente, se analizará el asunto a la luz de la crisis de migrantes y refugiados, resaltándose las ventajas del modelo de instrumento regional vinculante, con foco en las causas y soluciones duraderas. Se sostendrá que una amplia participación de los actores involucrados, como son la población desplazada y grupos armados no estatales, ofrecería perspectivas alentadoras, considerando las potenciales ventajas que su involucramiento podría conllevar.

Palabras clave: desplazamientos internos forzados, derecho internacional, conflictos armados, Convención de Kampala, instrumentos regionales, participación, grupos armados.

ABSTRACT: This paper analyses the issue of forced internal displacement, caused by armed conflicts and other situations of violence. After exposing the legal framework and its main weaknesses, some of the responses the international community has provided will be presented, such as the Kampala Convention. Afterwards, the matter will be studied in light of the migrants and refugees crisis, highlighting the advantages of a regional binding instrument, focusing on the causes and durable solutions. It will be argued that a wide participation of the actors involved, such as the displaced population and non-state armed groups, may offer encouraging perspectives, considering the potential benefits that its involvement may entail.

Key words: Forced Internal Displacements, International Law, Armed Conflicts, Kampala Convention, Regional Instruments, Participation, Armed Groups.

RÉSUMÉ: Le présent travail analyse les déplacements internes forcés à cause des conflits armés et d'autres situations de violence. Après avoir présenté le cadre normatif et ses principales faiblesses, certaines des réponses de la communauté internationale seront présentées, en faisant accent sur la Convention de Kampala. Ensuite, une analyse de la crise des migrants et des réfugiés, en soulignant les avantages d'un instrument régional contraignant, spécialement sur les causes et les solutions durables. J'affirme qu'une grande participation des acteurs impliqués, tels que les populations déplacées et les groupes armés non étatiques, offrirait des perspectives encourageantes, compte tenu des avantages potentiels que leur implication pourrait impliquer.

Mots-clés: déplacement interne force, droit international, conflit armé, Convention de Kampala, instrument régional, participation, groupe armé. 


\section{INTRODUCCIÓN: LA PROBLEMÁTICA}

DE LOS DESPLAZAMIENTOS INTERNOS FORZADOS

A lo largo de los últimos veinte años, la cantidad de personas que se han visto forzadas a abandonar sus hogares y desplazarse dentro de las fronteras de su Estado de residencia, exhibe una considerable tendencia creciente. Actualmente, más de 40 millones de personas viven como población internamente desplazada (en adelante, PID) a causa de los conflictos armados, violencia generalizada y violaciones de derechos humanos. ${ }^{1}$

Esta situación afecta notablemente los derechos de quienes se han visto obligados al desarraigo y representa una problemática caracterizada por no haber hallado una solución duradera, que permita abordar el fenómeno mediante perspectivas que trasciendan la mera asistencia humanitaria cortoplacista. En tal sentido, resulta pertinente examinar las vías a través de las cuales la comunidad internacional ha intentado responder al asunto, así como la efectividad de las mismas, a fin de explorar como alternativa viable la adopción de normas jurídicamente vinculantes, y en caso afirmativo, las particularidades que éstas deberían contemplar.

Es así como el presente trabajo se propone como punto de partida para examinar los aspectos centrales de los desplazamientos internos forzados y su regulación actual. La hipótesis central que guiará el estudio es que, las respuestas de la comunidad internacional ensayadas hasta el momento se han concentrado primordialmente en las consecuencias, antes que, en las causas, adoptando un enfoque de corto plazo y con poca participación de los actores concernidos; lo cual ciertamente no ha contribuido al mejoramiento de la situación. En ese orden de ideas, se sostendrá que soluciones duraderas basadas en las causas, con involucramiento de las diferentes partes y expresadas en convenciones regionales, como la Convención de Kampala, ${ }^{2}$ pueden allanar el camino hacia estándares de protección más

1 Consejo de Derechos Humanos de la Asamblea General de la ONU, "Informe de la Relatora Especial sobre los derechos humanos de los desplazados internos", A/HRC/38/39, 38o. período de sesiones, 11 de abril de 2018, párr. 17.

2 Convención de la Unión Africana para la Protección y la Asistencia de los Desplazados Internos en África, adoptada por la Cumbre Extraordinaria de la Unión Africana en Kampala, 
DOI: http://dx.doi.org/10.22201/iij_.24487872e_2020.20.14484

específicos y efectivos, según viene consignándose en los últimos informes de la Relatoría Especial sobre los derechos humanos de los desplazados internos de las Naciones Unidas (en adelante, "Relatoría Especial").

\section{MARCO NORMATIVO: CONFLUENCIA DE REGÍMENES \\ Y LOS PRINCIPIOS RECTORES DE 1998}

Los desplazamientos internos forzados pueden originarse en una multiplicidad de causales, pero a los efectos de este documento, sólo se considerarán las consecuencias acarreadas por un conflicto armado, situaciones de violencia generalizada y violaciones de derechos humanos.

Sin dudas, los desplazamientos internos conforman una problemática multifacética, que abarca diferentes etapas, todas las cuales transcurren dentro de los límites territoriales de un mismo Estado. Ante la ausencia de un régimen jurídico vinculante dedicado específicamente al asunto, el contenido de las obligaciones de los Estados sobre la PID se nutre de cuerpos normativos con estrecha vinculación entre sí: Derecho Internacional Humanitario (en adelante, DIH), Derecho Internacional de los Derechos Humanos (en adelante, DIDH), Derecho Internacional Penal (en adelante, DI Penal), y subsidiariamente por analogía, Derecho Internacional de los Refugiados.

En primer lugar, el DIH, destinado a regir en situaciones de conflictos armados, establece convencionalmente la prohibición de desplazar forzadamente a la población como consecuencia del conflicto armado y fija las excepciones, que sólo pueden consistir en proteger la seguridad de las personas o razones militares imperativas, lo cual es aplicable a aquellos de índole internacional como también no internacional. ${ }^{3} \mathrm{El}$ Comité Internacional de la Cruz Roja ha entendido que tales normas

Uganda, el 22 de octubre de 2009 (en adelante, “Convención de Kampala”).

3 Convenio de Ginebra relativo a la Protección Debida a las Personas Civiles en Tiempo de Guerra, 12 de agosto de 1949, artículo 49; Protocolo Adicional II a los Convenios de Ginebra de 1949 relativo a la Protección de las Víctimas de los Conflictos Armados sin Carácter Internacional, 8 de junio de 1977, artículo 17. 
integran el DIH consuetudinario. ${ }^{4}$ Por lo tanto, la existencia de causales taxativas que justifiquen el desplazamiento lleva a concluir que cualquier situación que se dé por fuera de las mismas sería injustificada, y por lo tanto, ilegal.

En segundo término, los desplazamientos internos forzados involucran al DIDH, aplicable tanto en tiempos de paz como en conflictos armados, ${ }^{5}$ al vulnerar derechos tales como circulación y residencia, contenidos en instrumentos universales, como también regionales. Este régimen resguarda también la integridad y libertad de la PID, que la protege contra ataques a su libertad sexual, trabajo forzado y detención arbitraria. Asimismo, existen derechos económicos, sociales y culturales que deben ser garantizados. El efectivo goce de los derechos descritos suele verse amenazado y/u obstaculizado por la situación de desplazamiento, lo que ubica a la población en una situación especial de vulnerabilidad.

A su turno, el DI Penal también se ocupa de determinar la responsabilidad que le cabe al individuo que genera el desplazamiento de la población civil por razones no autorizadas legalmente, en la tipificación como crimen de guerra. También reprocha la conducta como crimen de lesa humanidad de deportación o traslado forzoso de población, de cumplirse con los elementos previstos en el Estatuto de Roma, ${ }^{6}$ y bajo aplicación del principio de complementariedad.

Como viene de decirse, no existe actualmente un régimen jurídicamente vinculante y universal, que aborde específicamente los desafíos planteados por los desplazamientos internos forzados. Sin embargo, lo más cer-

4 Henckaerts, Jean-Marie y Doswald-Beck, Louise, Customary International Humanitarian Law, Nueva York, Cambridge University Press, 2005, pp. 457-474.

5 "Si bien se ha expresado que la aplicación del DIH obsta la plenitud de normas de derechos humanos, hoy se tratan de posiciones minoritarias, pues la Corte Internacional de Justicia (en adelante, CIJ) expresó que la aplicación del DIH no excluye la vigencia de los preceptos del DIDH, sin perjuicio de la posibilidad de suspender la vigencia de ciertas normas de éste en Estados de excepción”. CIJ, “Consecuencias jurídicas de la construcción de un muro en el territorio palestino ocupado”, Opinión Consultiva del 9 de julio de 2004, párr. 106.

6 La deportación forzada como crimen de guerra está prevista en los artículos 8.2.a.vii y 8.2.e.viii, para conflictos armados de índole internacional y no internacional, respectivamente; y está tipificado como crimen de lesa humanidad en el artículo 7.1.d, todos del Estatuto de Roma de la Corte Penal Internacional. 
cano a ello está dado por los Principios Rectores de los Desplazamientos Internos, adoptados por la entonces Comisión de Derechos Humanos, ${ }^{7}$ los cuales "identifican y refuerzan la intersección de las garantías del DIH y DIDH para la PID”. ${ }^{8}$ Tanto la definición allí ofrecida, ${ }^{9}$ como los principios son aceptados como el régimen más extenso de protección internacional en un nivel global ${ }^{10} \mathrm{y}$ han motivado la adopción de cierta normativa a nivel nacional e internacional. ${ }^{11}$

Los Principios Rectores prohíben el desplazamiento interno forzado de la población, por fuera de las causales taxativas, ${ }^{12}$ y enuncian las obligaciones de los Estados en la eventualidad de que el desplazamiento ocurra, como la protección de derechos tales como la vida, integridad, libertad, seguridad. Además, debe preservarse el acceso a la salud, educación, el respeto por sus creencias religiosas y el resguardo de la unidad familiar, sumado a la prohibición de cualquier tipo de utilización de la población civil con fines militares

7 Comisión de Derechos Humanos de la Asamblea General de la ONU, "Principios Rectores de los desplazamientos internos", E/CN.4/1998/53/Add.2, 53o. período de sesiones, 11de febrero de 1998 (en adelante, "Principios Rectores").

8 Dieng, Adama, "Protecting Internally Displaced Persons: The Value of the Kampala Convention as a Regional Example”, International Review of the Red Cross, vol. 99, núm. 204, 2017, p. 268 (traducción propia).

9 “...se entiende por desplazados internos las personas o grupos de personas que se han visto forzadas u obligadas a escapar o huir de su hogar o de su lugar de residencia habitual, en particular como resultado o para evitar los efectos de un conflicto armado, de situaciones de violencia generalizada, de violaciones de los derechos humanos o de catástrofes naturales o provocadas por el ser humano, y que no han cruzado una frontera estatal internacionalmente reconocida". "Principios Rectores de los desplazamientos internos", E/CN.4/1998/53/ Add.2, 11 de febrero de 1998, párr. 2.

10 Dieng, Adama, op. cit., p. 269.

11 Algunos Estados, como Colombia, Alemania e Irak, se han expresado en modo favorable a su fuerza vinculante. Al respecto, véase Global Protection Cluster, "Regulatory Frameworks on Internal Displacement. Global, Regional and National Developments”, 2016, p. 9. Disponible en: http://www.globalprotectioncluster.org/_assets/files/tools_and_guidance/Internal\%20Displacement/unhcr-gpc_reg_framework_idp.pdf, consultado el 29 de julio de 2018.

12 En este sentido, parte de la doctrina ha interpretado que la prohibición no sólo veda la orden, sino que además comprende la abstención de generar condiciones tales que lleven a la población civil a desplazarse. Entonces, tampoco estaría permitido alcanzar ese resultado por medios indirectos. Véase Willms, Jan, "Without Order, Anything Goes? The Prohibition of Forced Displacement in non-International Armed Conflict”, International Review of the Red Cross, vol. 91, núm. 875, 2009, pp. 547-565. 
en el marco del conflicto armado. Luego de finalizada la situación que originara el desplazamiento, los civiles tienen derecho a retornar voluntariamente a su lugar de origen, siendo su reasentamiento y reintegración garantizado por las autoridades competentes, junto con el derecho a recuperar su propiedad o de no ser posible, obtener una reparación. Asimismo, los desplazados pueden elegir reasentarse voluntariamente en otra parte del país.

\section{DificulTAdES QUE PRESENTA EL ABORDAJE DE LA PROBLEMÁTICA}

Al tiempo de aproximarse al estudio de los desplazamientos internos forzados, no puede soslayarse que los Principios Rectores pertenecen al dominio del soft law, por lo que no son jurídicamente vinculantes, sin perjuicio de la posible aceptación material de su contenido. De ello se deriva que sus preceptos no han establecido mecanismos de rendición de cuentas ni de atribución de responsabilidades, como así tampoco un monitoreo de esos principios.

Esta mélange de normas pertenecientes a diferentes disciplinas del derecho internacional, sirve para proveer fundamentos jurídicos que, al entrelazarse, ensayan una respuesta legal para la PID. Sin embargo, al tomar un poco de cada rama, pero no constituir un régimen específico que atienda a las particularidades propias y desafíos que este fenómeno presenta, el abordaje jurídico se queda a mitad de camino.

Además, la propia naturaleza de las obligaciones de los Estados en materia de DIH y DIDH, que en su esencia le imponen límites al margen de acción en pos de proteger a la persona y les exigen adoptar medidas conducentes a ello, facilita explicar cierta falta de voluntad de estos sujetos de asumir nuevos deberes sobre desplazamientos internos, en pos de someterse a menos controles. ${ }^{13}$

Por otra parte, la población desplazada permanece en el territorio de un mismo Estado sin cruzar fronteras. Entonces éste, como responsable exclusivo de garantizar la protección de sus derechos según las obligaciones que

13 Al respecto, Kälin sostiene que "Elaborar tratados en el ámbito de derechos humanos se ha convertido en una tarea ardua y lenta”. Kälin, Walter, "El futuro de los Principios Rectores”, Revista Migraciones Forzadas, Diez años de los Principios Rectores del Desplazamiento Interno, 2008, p. 38. 
en materia de DIDH haya contraído, ${ }^{14}$ también puede limitar su goce. Y sin perjuicio de los mecanismos de denuncia y monitoreo previstos en las respectivas convenciones sobre la materia, los Estados encuentran con cierto margen de discrecionalidad para afrontar el desplazamiento forzado.

Ello supone una diferencia sustancial con la situación en la que se encuentran los migrantes y refugiados. ${ }^{15}$ A la luz de la actual crisis de gobernanza de las migraciones, pareciera que la incipiente atención de la comunidad internacional se halla concentrada en los migrantes y refugiados, lo cual ha resultado en la reciente adopción del Pacto Mundial para una Migración Segura, Ordenada y Regular (en adelante, Pacto Mundial sobre Migración), en Marruecos, durante diciembre de 2018. En este sentido, es apropiado cuestionarse si el cruzar una frontera, dejando así representar un asunto a tratar en la jurisdicción de un sólo Estado, resulta necesario para atraer la atención de la comunidad internacional. ${ }^{16}$ Con lo expuesto, no pretende desconocerse que la migración, bajo ciertas condiciones, coloque a la persona en una situación de gran vulnerabilidad, pero se ha reconocido que muchos refugiados o migrantes, primero son desplazados internos, ${ }^{17}$ y no debería aguardarse a que abandonen el Estado en que se encuentran para atender su situación.

14 A las cuales se añaden aquellas atinentes al DIH si la situación cumple con las condiciones legalmente requeridas.

15 La primera diferencia está dada por la existencia de un marco normativo universal específico para refugiados, conformado por la Convención sobre el Estatuto del Refugiado de 1951 y su Protocolo de 1967.

16 Un argumento a favor de esta tendencia reciente se basa en la teoría de las responsabilidades compartidas, bajo la cual los Estados tienen deberes comunes y particulares compartidos en el proceso migratorio, sin que recaiga la carga sobre uno sólo. Véase Pacto Mundial sobre Migración, diciembre de 2018, párrs. 11 y 12.

17 "La vinculación entre el desplazamiento interno y el movimiento transfronterizo es clara. Las personas que cruzan las fronteras internacionales como solicitantes de asilo a menudo comienzan sus peligrosas travesías como desplazados internos que huyen de los conflictos o la violencia". "Informe de la Relatora Especial sobre los derechos humanos de los desplazados internos”, A/HRC/38/39, cit., párr. 22. 


\section{RESPUESTAS INTENTADAS EN EL MARCO DE NACIONES UNIDAS. ALGUNAS DEBILIDADES}

A partir del relevamiento de los recientes informes anuales de la Relatoría Especial y de algunos reportes emanados de organizaciones afines a la temática, se desprenden ciertos patrones comunes en el abordaje de la cuestión. Estos se detallan brevemente a continuación, consignándose ciertas falencias exhibidas en la implementación, que surgen de los propios documentos y de la opinión del suscripto.

En primer lugar, la búsqueda de soluciones duraderas para el desplazamiento forzado ha constituido el denominador común de las respuestas. ${ }^{18}$ Parecería un reconocimiento, explícito o tácito, de que las propuestas intentadas han estado marcadas por una perspectiva a corto plazo, admitiéndose que, si bien la asistencia humanitaria puede paliar ciertos efectos negativos inmediatos, se necesita un esfuerzo mayor para prevenir que la situación se repita.

Si bien hace algunos años las soluciones propuestas consistían mayormente en lograr el retorno al lugar de origen, la integración local o el reasentamiento en otra parte del país, ${ }^{19}$ con el tiempo el contenido de una respuesta a largo plazo ha ido expandiéndose, con otras implicancias. A la vez, ha ganado especificidad, pues el eje central del informe anual de 2014 fue la búsqueda de soluciones duraderas para desplazados en entornos urbanos, bajo el entendimiento de que este espacio presenta desafíos propios, como los riesgos de violencia sexual y la falta de acceso igualitario a

18 "Una solución duradera se logra cuando los desplazados internos dejan de necesitar asistencia o protección específicas vinculadas con su situación de desplazamiento y pueden disfrutar de sus derechos humanos sin ser discriminados por esa condición”. Consejo de Derechos Humanos de la Asamblea General de la ONU, "Informe del representante del secretario general sobre los derechos humanos de los desplazados internos”, A/HRC/13/21/ Add. 4, 13o. período de sesiones, 29 de diciembre de 2009, p. 2.

19 Asamblea General de Naciones Unidas, "Informe del Relator Especial sobre los derechos humanos de los desplazados internos”, A/68/225, 68o. período de sesiones, 31 de julio de 2013, párr. 23, que recoge lo fijado en el Principio Rector núm. 28.1. 
derechos tales como salud, educación y empleo, ${ }^{20}$ entre otros. Ello exhibe que cada terreno demanda respuestas a medida del mismo.

Otro de los asuntos presentes constituye la brecha que separa la fase de auxilio inmediato humanitario para la población, y la etapa de asistencia para el desarrollo, ${ }^{21}$ cuyo fin es lograr el sostenimiento en el tiempo de las personas afectadas tras la emergencia. ${ }^{22}$ En este sentido, se ha enfatizado la necesidad de integrar los esfuerzos de desarrollo desde el inicio del desplazamiento, esencial para estimular la resiliencia y la autonomía de los desplazados. ${ }^{23}$

En tercer lugar, el concepto que ha recibido mayor elaboración en el último lustro fue la necesidad de fomentar una participación más activa de los desplazados. Se reclamó que puedan elegir libremente y con conocimiento de causa la solución duradera que los atañe ${ }^{24}$ y el restablecimiento de su capacidad de actuación mediante procesos de consulta y participación. Para eso, deviene necesaria la recolección de datos, en miras a la elaboración de perfiles. ${ }^{25}$

Es así como en el informe de 2017, la Relatoría Especial esbozó los fundamentos y principios que deben regir la participación de la población desplazada, señalando que constituye un componente fundamental de los nuevos enfoques de las respuestas. Esta debe ocurrir en todas las fases del

20 Asamblea General de Naciones Unidas, "Informe del Relator Especial sobre los derechos humanos de los desplazados internos”, A/69/295, 69o. período de sesiones, 11 de agosto de 2014, párrs. 34-36.

21 Asamblea General de Naciones Unidas, "Informe del Relator Especial sobre los derechos humanos de los desplazados internos”, A/68/225, cit., párr. 29.

22 Consejo de Derechos Humanos de la Asamblea General de la ONU, "Informe de la Relatora Especial sobre los derechos humanos de los desplazados internos”, A/HRC/38/39, cit., párr. 63.

23 Consejo de Derechos Humanos de la Asamblea General de la ONU, "Informe del Relator Especial sobre los derechos humanos de los desplazados internos”, A/HRC/32/35, 32o. período de sesiones, 29 de abril de 2016, párr. 48.

24 Asamblea General de Naciones Unidas, "Informe del Relator Especial sobre los derechos humanos de los desplazados internos”, A/69/295, cit., párr. 57.

25 Consejo de Derechos Humanos de la Asamblea General de la ONU, "Informe del Relator Especial sobre los derechos humanos de los desplazados internos”, A/HRC/32/35, cit., párrs. 82 y 83. 
desplazamiento, ser impulsada por los Estados, ${ }^{26}$ y comprende el diseño, la planificación y puesta en práctica de medidas orientadas hacia ellos; $;^{27}$ todo eso con una adecuada integración de género, edad, discapacidad y diversidad, ${ }^{28}$ pues se entiende que el desplazamiento exacerba cuestiones discriminatorias cotidianas. ${ }^{29}$ Luego se destacó el rol de los desplazados como agentes y asociados activos de su propia recuperación, con énfasis en su empoderamiento a fin de romper el ciclo de dependencia de la ayuda. ${ }^{30}$

No puede ignorarse que los sucesivos informes han procurado recordar la responsabilidad de los Estados en el desplazamiento interno, destacando ciertas dificultades comunes que atraviesan al lidiar con el asunto, tales como tener por duraderas algunas soluciones meramente transitorias, o promover el retorno al lugar de origen como primera medida. También se ha resaltado la falta de coordinación entre autoridades nacionales y municipales. ${ }^{31}$ Se ha resaltado que la soberanía nacional y la política interna no son excusas para desatender el asunto, y que resulta fundamental la incorporación de los Principios Rectores en la legislación y política nacional, como así también mejorar los marcos jurídicos regionales. ${ }^{32}$

De las cuestiones ventiladas en los párrafos precedentes, se desprende que coexisten respuestas que procuran hacer hincapié en las causas del problema, así como en sus consecuencias. Las primeras se han cimentado sobre un enfoque a largo plazo y los avances generados en este ámbito parecerían ser mínimos. Las segundas han sido implementadas con mayor celeridad, pero no siempre logran dotar de autonomía a la población des-

26 Asamblea General de Naciones Unidas "Informe de la Relatora Especial sobre los derechos humanos de los desplazados internos”, A/72/202, 72o. período de sesiones, 24 de julio de 2017, párrs. 33-45.

27 Ibidem, párr. 11.

28 Ibidem, párr. 75.

29 Consejo de Derechos Humanos de la Asamblea General de la ONU, "Informe de la Relatora Especial sobre los derechos humanos de los desplazados internos”, A/HRC/38/39, cit., párr. 29.

30 Ibidem, párr. 64.

31 Asamblea General de Naciones Unidas, "Informe del Relator Especial sobre los derechos humanos de los desplazados internos”, A/69/295, cit., párr. 38.

32 Consejo de Derechos Humanos de la Asamblea General de la ONU, "Informe de la Relatora Especial sobre los derechos humanos de los desplazados internos”, A/HRC/38/39, cit., párrs. 26-52. 
Esta revista forma parte del acervo de la Biblioteca Jurídica Virtual del Instituto de Investigaciones Jurídicas de la UNAM

DOI: http://dx.doi.org/10.22201/iij.24487872e_2020.20.14484

plazada ni alcanzan el umbral de estabilidad para garantizar que la situación no se repita.

\section{LA IMPORTANCIA DE LOS APORTES DE LA CONVENCIÓN DE KAMPALA}

En el marco de un asunto que, desde lo material, se inserta dentro de las fronteras de los Estados, estos resultan los primeros llamados a velar por la protección de la PID. Ello ha motivado a que los ojos de la comunidad internacional estén mayormente colocados sobre el accionar estatal, lo cual ubica las soluciones duraderas a los desplazamientos internos forzados en una lógica Estadocéntrica. A pesar de los avances en el abordaje, que reclaman una mayor participación de la población involucrada, ha sido escaso el lugar reconocido a los múltiples actores que desempeñan algún tipo de papel, ya sea como promotores, interesados o afectados por el desplazamiento, en el desarrollo del mismo. Los grupos armados no estatales ilustran este asunto.

Sin embargo, en el ámbito regional africano, notablemente afectado por la PID, la entonces Unión Africana adoptó en 2009 la Convención de Kampala como marco normativo para proteger y asistir a personas internamente desplazadas en el continente. Este tratado, único instrumento vinculante en la materia, articula obligaciones generales de los Estados en relación a la protección y asistencia de desplazados, de la Unión Africana, organizaciones internacionales, grupos armados y actores no estatales, durante y después del desplazamiento. ${ }^{33} \mathrm{Si}$ bien adopta la misma definición de PID que los Principios Rectores, éstos lo hacen desde una perspectiva de derechos de los desplazados, en tanto la Convención de Kampala “...se propone ser una herramienta para los sujetos obligados, reafirmando el rol primario de los Estados en atender el desafío y los roles complementarios de los otros actores"; ${ }^{34}$ estableciendo en consecuencia mecanismos de atribución de responsabilidad. Asimismo, contempla una multiplicidad de disparadores del desplazamiento, adjudicando a los Estados parte la responsabilidad de actuar sobre los factores que podrían generarlo. ${ }^{35}$

33 Dieng, Adama, op. cit., p. 273.

34 Ibidem, p. 275 (traducción propia).

35 Convención de Kampala, arts. 3.1.b y 4.4. 
En el contexto de las soluciones duraderas para la PID, la Convención de Kampala resulta una de las más significativas, destinada a fortalecer los marcos legales y políticos para proteger e incluir a los desplazados, asegurando su participación, y desarrollando su resiliencia y capacidad a nivel local. Prevé medidas de prevención, preparación y evaluación de riesgos y la cooperación entre las partes asociadas se efectúa desde el comienzo de la situación.

El tratado reconoce la posibilidad de que actores no estatales puedan ser responsables de violaciones a derechos de la PID, por lo que les impone obligaciones de abstención, ${ }^{36}$ sin que su mención en el instrumento implique reconocimiento normativo ni legitimación.

Para Adama Dieng, la imposición de obligaciones a actores no estatales en materia de desplazamiento puede deberse al rol vital desempeñado por grupos armados en el gobierno de territorios, en la medida que ejercen muchas funciones tradicionalmente atribuidas a los Estados. Entonces, el propósito de la Convención de Kampala sería asegurar la protección de la PID, independientemente del carácter de las autoridades competentes a cargo. ${ }^{37}$

En opinión del suscripto, la adopción del instrumento no sólo resulta trascendental en lo que hace a la previsión de un marco jurídico obligatorio, si bien regional, sobre los desplazamientos internos. Su valor adicional radica en establecer específicamente un conjunto de conductas que los miembros de grupos armados deberán abstenerse de realizar, reconociéndolos como agentes susceptibles de causar desplazamientos. El tratado se refiere a ellos, no en modo conciliatorio ni atribuyéndoles derechos, pero la propia inclusión del colectivo conlleva un enfoque pragmático bajo el cual se reconoce que su accionar incide en la población afectada por el desplazamiento. $^{38}$

36 Ibidem, art. 7.5.

37 Dieng, Adama, op. cit., p. 276.

38 Es pertinente resaltar que en un reporte elaborado por la ONG Geneva Call, se examinaron las diversas relaciones existentes entre grupos armados no estatales y poblaciones desplazadas, determinándose que el desplazamiento no siempre es un resultado buscado por el grupo armado y que, bajo ciertas circunstancias, puede resultar legal. Se procuró además derribar ciertos preconceptos sobre la presunta incapacidad de grupos armados de respetar el DIH, desagregando un papel que los reduce a meros promotores del desplazamiento. Véase Ruaudel, Hélöise, Armed non-State Actors and Displacement in Armed Conflict, Geneva Call, 2013. 
En este punto conviene detenerse un momento para recordar que la mayoría de los conflictos armados actuales son de carácter no internacional, donde al menos una de las partes es un actor no estatal. Estos no han participado en la elaboración de normas convencionales de DIH, ni su práctica se acepta como válida para la formación de la costumbre internacional. Sin embargo, diferentes teorías han intentado atribuirles deberes bajo el derecho internacional, supliendo así esta aparente ausencia. ${ }^{39}$ Más allá de que no pueda asignárseles las mismas obligaciones que tienen los Estados, por su diferente naturaleza como sujetos del derecho internacional, se admite que estos grupos existen y si ejercen autoridad asimilable a la estatal, deben velar por los derechos de la población civil a su cargo, tal como sugiere Dieng. Incluirlos explícitamente en la elaboración de normas vinculantes representa un primer paso, a la luz de debates actuales que procuran establecer qué obligaciones les resultan exigibles en contextos de detención.

En otro orden de ideas, el potencial de la Convención de Kampala como ejemplo a seguir por otras regiones para la formulación de tratados sobre la cuestión, interpela a la comunidad internacional sobre la posibilidad de que tal vez la respuesta no provenga del sistema universal de Naciones Unidas, sino que sea regional. Algunos avances que confirman esta hipótesis han sido exhibidos en 2015, en el marco de distintos foros de consulta regional organizados por el World Humanitarian Summit (en adelante, "WHS") para Latinoamérica y el Caribe, ${ }^{40}$ y para la zona del Pacífico. ${ }^{41}$

Disponible en: https://genevacall.org/wp-content/uploads/dlm_uploads/2013/12/Armed-nonState-actors-and-displacement-in-armed-conflict1.pdf, consultado el 29 de julio de 2018.

39 A modo ilustrativo, se pueden señalar las siguientes: equality of belligerents, sliding scale obligations, common but differentiated obligations, desarrolladas en el texto de Sassòli, Marco y Shany, Yuval, "Should the Obligations of States and Armed Groups under International Humanitarian Law Really be Equal”, International Review of the Red Cross, vol. 93, no. 882, 2011, pp. 425-436.

40 World Humanitarian Summit, "Regional Consultation for Latin America-Caribbean", Ciudad de Guatemala, 5 y 6 de mayo de 2015, p. 7.

41 World Humanitarian Summit, "Regional Consultation for the Pacific", final report, Auckland, Nueva Zelanda, 30 de junio al 2 de julio de 2015, p. 26. 


\section{Algunas CONSIDERACIONES ADICIONALES Y PERSPECTIVAS}

Un breve estudio sobre los desplazamientos internos forzados no estaría completo sin referirse al panorama más amplio, constituido por la crisis global, que atraviesan los migrantes y refugiados, y cuya perspectiva de adopción normativa está signada por el Pacto Mundial, sin perjuicio de su carácter no vinculante.

De acuerdo con la Declaración de Nueva York ${ }^{42}$ y el Pacto Mundial adoptado por más de 150 Estados en diciembre de 2018, la población internamente desplazada no se halla incluida entre los sujetos protegidos, pues el documento está orientado a migrantes y refugiados, esto es, personas que han cruzado una frontera internacional. Así, se puede confirmar que la aparición de normas vinculantes de protección para la PID no parecería una posibilidad cercana, al menos en el ámbito universal, ${ }^{43}$ a pesar de los esfuerzos de la Relatoría Especial para su mención en el Pacto Mundial. ${ }^{44}$ En refuerzo de ello, se ha destacado también la ausencia de una referencia explícita en los Objetivos de Desarrollo Sostenible de las Naciones Unidas. ${ }^{45}$

No obstante, el potencial del Pacto Mundial radica en el impulso que la temática pueda adquirir, de modo tal de incentivar la adopción de instrumentos regionales sobre la movilidad humana, sin reparar en su carácter interno o transfronterizo, que puedan contemplar las necesidades propias y cualidades de cada continente.

42 Asamblea General de Naciones Unidas, "Declaración de Nueva York para los Refugiados y Migrantes”, A/71/L.1, 71o. período de sesiones, 13 de septiembre de 2016.

43 "Desde el punto de vista jurídico, institucional y político, la distinción entre derechos humanos, de aplicación fundamentalmente en tiempos de paz, y el derecho humanitario para los tiempos de conflicto armado era esencial, por lo que cabía esperar que muchos países y organizaciones se opusieran con firmeza a cualquier intento de unir ambas áreas jurídicas en un único convenio de las Naciones Unidas”. Kälin, Walter, op. cit., p. 39.

44 Con fecha del 12 de marzo de 2018, la Relatora Especial presentó una carta abierta en la que hizo notar la ausencia de menciones acerca de los desplazamientos internos en el Pacto Mundial de Migración e instó a los Estados miembros a suplir esta omisión e incluirlo expresamente dentro del objetivo 2 del instrumento.

45 Consejo de Derechos Humanos de la Asamblea General de la ONU, "Informe de la Relatora Especial sobre los derechos humanos de los desplazados internos”, A/HRC/38/39, cit., párr. 61 
Este potencial estímulo resulta de vital importancia a la luz del último informe de la Relatoría Especial de Naciones Unidas, en el que realza la importancia de profundizar la aplicación y los alcances de los Principios Rectores, tras veinte años de vigencia. Ello coincide con la opinión de Dieng, quien sugiere que, estos se podrían reforzar para adaptarlos a las nuevas realidades y desarrollos en derecho internacional, a fin de reflejar las tendencias actuales. ${ }^{46}$

El mencionado autor va un paso más allá cuando sostiene que un instrumento jurídicamente vinculante sería además apropiado, ya que el número de PID ha sobrepasado el de refugiados convencionalmente reconocidos bajo el Derecho Internacional y el amparo del ACNUR. ${ }^{47}$

\section{REFLEXIONES FINALES}

Habiendo transcurrido dos décadas desde el surgimiento de los Principios Rectores, la Relatoría Especial ha observado que la tendencia mundial es desalentadora. A fin de remediar la situación, llamó a los Estados y a la comunidad internacional a examinar las causas del aumento de desplazados y realizar un esfuerzo mayor por impedirlo. ${ }^{48}$ Se dijo que la tendencia a recurrir a normas de derechos humanos no refleja adecuadamente la situación específica que atraviesa la PID, ni tampoco su vulnerabilidad y los desafíos. ${ }^{49}$

Si bien no pueden soslayarse los aportes del DIDH en cuanto a los derechos de la población desplazada, ni lo proveniente del DIH sobre la prohibición de desplazar población con motivo del conflicto armado, lo cierto es que ninguna de estas ramas tiene como meta brindar respuestas basadas en las causas de los desplazamientos, como así tampoco ofrecer soluciones duraderas. Es así como un ordenamiento específico sobre desplazamientos

46 Dieng, Adama, op. cit., p. 279.

47 Idem.

48 Consejo de Derechos Humanos de la Asamblea General de la ONU, "Informe de la Relatora Especial sobre los derechos humanos de los desplazados internos”, A/HRC/38/39, cit., párr. 19.

49 Ibidem, párr. 58. 
internos podría suplir ciertos vacíos normativos que la mélange descrita no logra atender.

Esta tendencia hacia la especificidad se inserta en la llamada fragmentación del derecho internacional, ${ }^{50}$ cuyo reflejo más reciente y cercano es el Pacto Mundial, donde la comunidad internacional entiende que, la responsabilidad de ciertas cuestiones es compartida. No pretende ignorarse que ello se debe al involucramiento de más de un Estado en asuntos migratorios, en tanto los desplazamientos internos ocurren, por definición, dentro de un solo Estado.

Sin embargo, tal vez esta noción de responsabilidad compartida pueda guiar el desarrollo normativo venidero, bajo el precepto de que los Estados no pueden lidiar solos con el problema y que éste, por sus implicancias, ya no es un asunto para resolver exclusivamente fronteras adentro; lo que así debe abordarse por la comunidad internacional, coincidiendo entonces con lo planteado por la Relatoría Especial. ${ }^{51}$ En opinión del suscripto, la soberanía estatal es mucho más que, potestades y prerrogativas. Comprende primordialmente la responsabilidad, y esta se incrementa cuando de proteger derechos humanos se trata.

Ciertamente, la adopción de un instrumento jurídicamente vinculante en el ámbito universal no parece una opción posible hoy en día. No obstante, con 65 millones de personas desplazadas, la regulación internacional debe atender de algún modo la creciente movilidad humana. Considerando el valor de la Convención de Kampala y lo observador por la Relatoría

50 "Por una parte, la fragmentación crea el peligro de que surjan normas, principios, sistemas de normas y prácticas institucionales contradictorios e incompatibles. Por otra parte, refleja la expansión de la actividad jurídica internacional en nuevos ámbitos y la consiguiente diversificación de sus objetos y de sus técnicas". Comisión de Derecho Internacional de la Asamblea General de la ONU, "Fragmentación del derecho internacional: dificultades derivadas de la diversificación y expansión del derecho internacional”, Informe del Grupo de Estudio de la Comisión de Derecho Internacional, A/CN.4/L.682, 58o. período de sesiones, 2006, párr. 246.

51 "Por consiguiente, es imprescindible que el desplazamiento interno se entienda no solo como un desafío para unos pocos Estados afectados por el conflicto, la violencia o los desastres, o como una cuestión que atañe exclusivamente a los asuntos internos de los Estados, sino como un problema regional y en última instancia mundial, que tiene consecuencias para muchos países." Consejo de Derechos Humanos de la Asamblea General de la ONU, "Informe de la Relatora Especial sobre los derechos humanos de los desplazados internos", A/ $\mathrm{HRC} / 38 / 39$, cit., párr. 23. 
Especial, es factible avanzar hacia mayores compromisos internacionales que garanticen la protección de la PID, en los respectivos ámbitos regionales. Para asegurar mayores posibilidades de éxito, estos necesariamente deberán incluir la participación activa de la población afectada, pero también de todos los actores involucrados en el fenómeno, en miras a enriquecer el abordaje desde múltiples perspectivas.

Lo antedicho incluye a actores no estatales como grupos armados. $\mathrm{Su}$ innegable incidencia en los desplazamientos internos motivados por conflictos armados implora tenerlos en cuenta para elaborar preceptos vinculantes sobre el tema, no sólo para imponerles obligaciones negativas, sino también para visibilizar sus implicancias sociales y políticas y su capacidad de cumplir funciones humanitarias. ${ }^{52}$ Ello habilitaría a complejizar la noción Estadocéntrica, demostrando que la misma no es absoluta. A su vez, serviría para empezar a superar el enfoque pragmático y los argumentos basados en la mera conveniencia de respetar obligaciones que los Estados, y no estos grupos, han asumido. Sin embargo, debe avanzarse con cautela, pues la subjetividad internacional presenta limitaciones, que se suman a barreras políticas y a la imposibilidad de exigir a grupos armados obligaciones que ni siquiera pueden reputarse hoy en cabeza de los Estados.

\section{BIBLIOGRAFÍA}

Asamblea General de Naciones Unidas, "Informe de la Relatora Especial sobre los derechos humanos de los desplazados internos”, A/72 /202, 72 o. período de sesiones, 24 de julio de 2017.

Asamblea General de Naciones Unidas, "Informe del Relator Especial sobre los derechos humanos de los desplazados internos”, A/68/225, 680. período de sesiones, 31 de julio de 2013.

Asamblea General de Naciones Unidas, "Informe del Relator Especial sobre los derechos humanos de los desplazados internos”, A/69/295, 69o. período de sesiones, 11 de agosto de 2014.

52 Ruaudel, Hélöise, op. cit., p. 44. 
Esta revista forma parte del acervo de la Biblioteca Jurídica Virtual del Instituto de Investigaciones Jurídicas de la UNAM

Consejo de Derechos Humanos de la Asamblea General de la ONU, "Informe del representante del secretario general sobre los derechos humanos de los desplazados internos”, A/HRC/13/21/Add. 4, 13o. período de sesiones, 29 de diciembre de 2009.

Consejo de Derechos Humanos de la Asamblea General de la ONU, "Informe del Relator Especial sobre los derechos humanos de los desplazados internos”, A/HRC/32/35, 32o. período de sesiones, 29 de abril de 2016.

Consejo de Derechos Humanos de la Asamblea General de la OnU, "Informe de la Relatora Especial sobre los derechos humanos de los desplazados internos”, A/HRC/38/39, 38o. período de sesiones, 11 de abril de 2018 .

DiEnG, Adama, "Protecting Internally Displaced Persons: The Value of the Kampala Convention as a Regional Example”, International Review of the Red Cross, vol. 99, núm. 204, 2017.

Global Protection Cluster, "Regulatory Frameworks on Internal Displacement. Global, Regional and National Developments”, 2016. Disponible en: http://www.globalprotectioncluster.org/_assets/files/tools_ and_guidance/Internal\%20Displacement/unhcr-gpc_reg_framework_idp.pdf, consultado el 29 de julio de 2018.

Henckaerts, Jean-Marie y Doswald-BeCK, Louise, Customary International Humanitarian Law, Nueva York, Cambridge University Press, 2005.

KÄLIN, Walter, "El futuro de los Principios Rectores", Revista Migraciones Forzadas, Diez años de los Principios Rectores del Desplazamiento Interno, 2008.

RuAudel, Hélöise, Armed non-State Actors and Displacement in Armed Conflict, Geneva Call, 2013. Disponible en: https: / / genevacall.org/wp-content/uploads/dlm_uploads/2013/12/Armed-non-State-actors-and-displacement-inarmed-conflict1.pdf, consultado el 29 de julio de 2018.

SASSÒl, Marco y SHAnY, Yuval, "Should the Obligations of States and Armed Groups under International Humanitarian Law Really be Equal”, International Review of the Red Cross, vol. 93, no. 882, 2011.

WILlms, Jan, "Without Order, Anything Goes? The Prohibition of Forced Displacement in non-International Armed Conflict", International Review of the Red Cross, vol. 91, núm. 875, 2009. 
Esta revista forma parte del acervo de la Biblioteca Jurídica Virtual del Instituto de Investigaciones Jurídicas de la UNAM https://www.juridicas.unam.mx/ https://biblio.juridicas.unam.mx/bjv https://revistas.juridicas.unam.mx/

DOI: http://dx_doi.org/10.22201/iij_24.487872e_2020.20.14484

World Humanitarian Summit, "Regional Consultation for Latin America-Caribbean”, Ciudad de Guatemala, 5 y 6 de mayo de 2015.

World Humanitarian Summit, "Regional Consultation for the Pacific", final report, Auckland, Nueva Zelanda, 30 de junio al 2 de julio de 2015. 